\title{
Host hybridization alters specificity of cnidarian-dinoflagellate associations
}

\author{
Daniel J. Thornhill ${ }^{1, *}$, Katharine Doubleday ${ }^{1}$, Dustin W. Kemp ${ }^{2}$, Scott R. Santos ${ }^{3}$
}

${ }^{1}$ Department of Biology, Bowdoin College, 6500 College Station, Brunswick, Maine 04011, USA

${ }^{2}$ Odum School of Ecology, University of Georgia, Athens, Georgia 30602, USA

${ }^{3}$ Department of Biological Sciences, Auburn University, 101 Rouse Life Sciences Bldg., Auburn University, Alabama 36849, USA

\begin{abstract}
Scleractinian coral evolution is often characterized by alternating patterns of lineage diversification and fusion, thus leading to reticulate evolution. Although this pattern is hypothesized in many coral lineages, including the Montastraea annularis species complex, it is not known what effects cladogenesis and hybridization have on the symbioses between corals and their endosymbiotic dinoflagellates (genus Symbiodinium). To explore this, the genetic diversity of M. faveolata and M. annularis in the Upper Florida Keys, USA, and Exuma Cays, The Bahamas, was examined using a mtDNA intergenic region. The host genotypic data were then analyzed in relation to the diversity of the corals' Symbiodinium communities as determined by internal transcribed spacer region 2 (ITS2) and 3 microsatellite markers specific to Symbiodinium Clade B. M. faveolata and M. annularis in the Upper Florida Keys were genetically distinct from one another while these coral species in the Exuma Cays shared mtDNA haplotypes. These findings suggest possible regional differences in the degree of intergressive hybridization between $M$. faveolata and M. annularis. When Symbiodinium diversity was examined, Montastraea spp. from both regions shared Symbiodinium ITS2 genotypes; however, host-symbiont specificity was observed using higher resolution microsatellite markers. Specifically, M. faveolata and $M$. annularis from the Upper Florida Keys all harbored genetically distinct multilocus Clade B genotypes, whereas these 2 coral species in the Exuma Cays shared Clade B genotypes. Consequently, the degree of fine-scale specificity between Symbiodinium Clade B genotypes and Montastraea spp. appears to be governed by the degree of genetic distinction, and possibly hybridization, between these host 'species'.
\end{abstract}

KEY WORDS: Symbiosis - Reticulate evolution - Coral reef - Endosymbiosis • Montastraea • Symbiodinium $\cdot$ Scleractinia

Resale or republication not permitted without written consent of the publisher

\section{INTRODUCTION}

The evolution of many reef-building (i.e. scleractinian) corals has been shaped by alternations between cladogenesis and hybridization (reviewed in Willis et al. 2006), hypothetically leading to a reticulate pattern of evolution (Veron 1995). This pattern stems from a high potential for interspecies hybridization because the majority of corals reproduce via synchronous broadcast spawning of gametes, followed by external fertilization in the water column (Szmant 1986, Richmond \& Hunter 1990). As a result, corals experience few environmental or behavioral prezygotic barriers to interspecies fertilization. For instance, the Caribbean broadcasting species Acropora cervicornis and A. palmata are known to hybridize regularly, producing apparently sterile offspring (i.e. A. prolifera) that are morphologically intermediate between the parent species (van Oppen et al. 2000, Vollmer \& Palumbi 2002). Furthermore, strong genetic similarities among Caribbean Madracis (Diekmann et al. 2001) and Australian Platygyra (Miller \& Benzie 1997) may also provide evidence for such phenomena. In the case of closely related Indo-Pacific Acropora, widespread hybridization has led to complex evolutionary patterns that have hindered the demarcation of species boundaries 
(reviewed in Willis et al. 2006). Given this, it is not surprising that elucidating coral evolution has been especially challenging when different processes (i.e. isolation versus hybridization) occur contemporaneously in varying regions of the world (Benzie 1999).

One example of a broadcast-spawning scleractinian lineage with an intricate evolutionary history is the Montastraea annularis species complex. Members of this lineage occur throughout the Caribbean Sea and western Atlantic Ocean where they are major contributors to coral reef accretion (Goreau 1959). Although debate surrounds the taxonomic status of members within the complex (Knowlton et al. 1992, 1997, Szmant et al. 1997, Medina et al. 1999), 3 morphospecies have been formally described: $M$. annularis, $M$. faveolata and $M$. franski. Notably, recent morphological and molecular genetic studies indicate these 'species' hybridize at a higher frequency in the Bahamas than in Panama (Budd \& Pandolfi 2004, Fukami et al. 2004). This has lead to the suggestion that a genetic isolation versus hybridization gradient exists for Montastraea spp., resulting in differing 'species' boundaries across the Caribbean (Fukami et al. 2004). However, the frequency of hybridization between these corals at other localities, as well as how it may influence other aspects of their biology, remains to be determined.

One interesting, yet unexplored, question is whether hybridization among scleractinian 'species' affects the intimate relationship they share with endosymbiotic dinoflagellates. Belonging to the genus Symbiodinium, these symbionts represent a diverse group of photosynthetic eukaryotic microbes that are associated with numerous protistan and invertebrate hosts (reviewed in Trench 1993, Stat et al. 2006) and which play a pivotal role in the high growth and calcification rates of scleractinians (reviewed in Barnes \& Chalker 1990, Trench 1993). Based on molecular genetic evidence, Symbiodinium can be divided into 8 major clades (i.e. A to $\mathrm{H}_{\text {; }}$ reviewed in Coffroth \& Santos 2005), each of which can contain numerous 'types' (defined by the sequences of their internal transcribed spacer [ITS] regions) and with many 'types' proposed to be distinct species (LaJeunesse 2001, Sampayo et al. 2009, but see Pochon et al. 2007, Correa \& Baker 2009). In terms of their symbiotic biology, certain 'types', known as 'specialists', associate with only a single host species whereas others, referred to as 'generalists', form symbioses with more than a single host species (reviewed in Stat et al. 2006). Conversely, many hosts harbor only a single Symbiodinium 'type' throughout their geographic and depth ranges, while some are capable of symbioses with multiple Symbiodinium lineages either occurring separately or simultaneously (e.g. LaJeunesse 2002, Goulet 2006, Thornhill et al. 2008). Although a considerable body of work on Symbiodinium diversity and distributions has accumulated, little research has attempted to integrate such data into the genetics of the host populations from which they were acquired (but see Barshis et al. 2010, Bongaerts et al. 2010).

Overall, 'species' of the Montastraea annularis complex are among the most flexible scleractinians known when it comes to their Symbiodinium complements; symbioses with both 'specialist' and 'generalist' ITS 'types' from Clades A, B, C and D have been reported across these corals' depth and geographic ranges (Toller et al. 2001, LaJeunesse 2002, Thornhill et al. 2006a). Despite this, Thornhill et al. (2009) observed species-specific Symbiodinium Clade B genotypes, identified via microsatellites, associated with $M$. annularis and $M$. faveolata from the Upper Florida Keys, USA. In contrast, Symbiodinium Clade B microsatellite genotypes were shared between these Montastraea species in the Exuma Cays, The Bahamas (Thornhill et al. 2009). Such observations led to the hypothesis that specificity in the Symbiodinium Clade B associations of $M$. annularis and $M$. faveolata is inversely correlated to the degree of hybridization between the 2 hosts (Thornhill et al. 2009). If correct, $M$. annularis and M. faveolata in the Florida Keys are hypothesized to be genetically distinct, whereas the same 2 'species' should be genetically similar in the Exuma Cays (following Fukami et al. 2004). In the present study, these predictions were tested in the Florida Keys and Exuma Cays by examining the genetic diversity and structure of $M$. annularis and $M$. faveolata in the context of their corresponding population-level Symbiodinium Clade B diversity.

\section{METHODS}

Study sites and collection of Montastraea faveolata and $M$. annularis. Montastraea faveolata and M. annularis were sampled from 5 western Atlantic Ocean locations, including 3 reefs in the Upper Florida Keys and 2 reefs in the Exuma Cays (Fig. 1). In the Florida Keys, these sampling locations were the inshore Admiral Patch Reef (ADM; 1 to $2 \mathrm{~m}$ depth, $25.045^{\circ} \mathrm{N}$, $80.395^{\circ} \mathrm{W}$ ), offshore Little Grecian Reef (LG; 3 to $4 \mathrm{~m}$ depth, $25.119^{\circ} \mathrm{N}, 80.302^{\circ} \mathrm{W}$ ) and the deeper water Alligator Reef (AG; $12 \mathrm{~m}$ depth, $\left.24.842^{\circ} \mathrm{N}, 80.624^{\circ} \mathrm{W}\right)$. Similarly, the inshore North Norman's Patch (NP; 2 to $4 \mathrm{~m}$ depth, $23.791^{\circ} \mathrm{N}, 76.137^{\circ} \mathrm{W}$ ) and deeper water South Perry Reef (SP; 12 to $15 \mathrm{~m}$ depth, $23.775^{\circ} \mathrm{N}$, $76.090^{\circ} \mathrm{W}$ ) were sampled in the Exuma Cays.

On each reef, 6 colonies of both Montastraea faveolata and $M$. annularis, each separated by approximately 4 to $50 \mathrm{~m}$ from the nearest conspecific individual, were sampled by SCUBA or snorkel diving (a total of 
(a) N. Caribbean / W. Atlantic

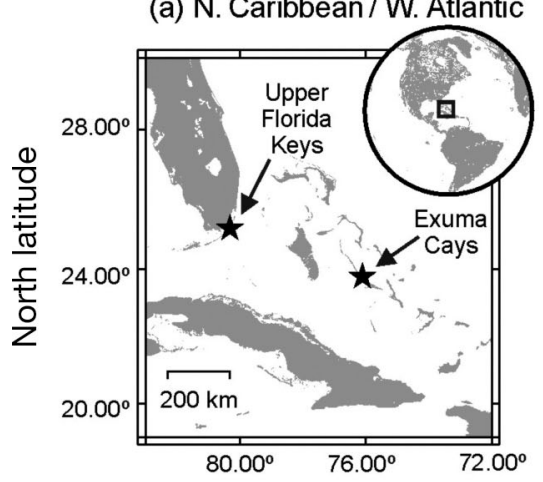

(b) Upper Florida Keys, USA

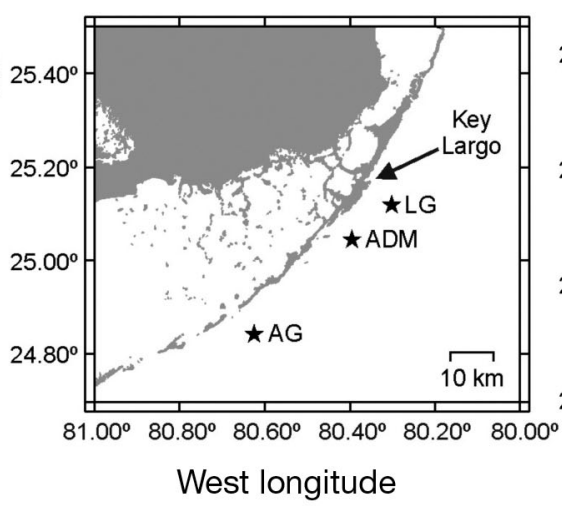

(c) Exuma Cays, Bahamas

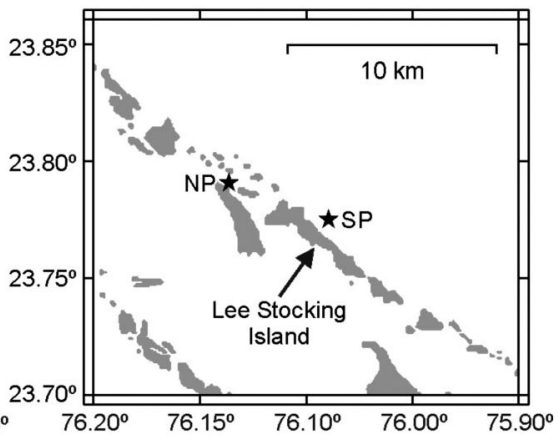

Fig. 1. Montastraea faveolata and M. annularis. (a) Regional and (b,c) local collection sites. Reef abbreviations for the Upper Florida Keys are: LG, Little Grecian Reef; ADM, Admiral Patch Reef; AG, Alligator Reef. Abbreviations for the Exuma Cays are: NP, North Norman's Patch Reef; SP, South Perry Reef. Figure is adapted from Thornhill et al. (2009)

30 colonies for $M$. faveolata and 30 for $M$. annularis). Colonies were specifically selected based on colony features and corallite morphology characteristic of either M. faveolata or $M$. annularis as described by Knowlton et al. (1992). While selecting morphologically distinct colonies helps ensure correct identification of each 'species', this approach potentially underestimates the degree of genetic similarity between Montastraea species. Therefore, presented results should be considered minimum measures of genetic similarity within a 'species' for a region. Approximately $10 \mathrm{~cm}^{2}$ fragments were removed by means of a hammer and chisel, and care was taken to ensure that the same relative position (i.e. unshaded colony tops) was sampled from each colony. Upon collection, fragments were placed in labeled plastic bags filled with seawater and immediately transported to the laboratory in an insulated cooler for processing.

Nucleic acid extraction, PCR and DNA sequencing. Each sample was split into 2 fragments. Tissue was removed from one fragment using a recirculating Waterpik (Water Pik) with $0.45 \mu \mathrm{m}$ filtered seawater and the 'blastate' pulsed for 1 to $4 \mathrm{~s}$ with a tissue homogenizer (Polytron Kinematica Tissue Homogenizer $^{\mathrm{TM}}$, Brinkmann Instruments) to disperse mucopolysaccharides. Symbiodinium cells for molecular analyses were concentrated from the saltwater 'blastate' via centrifugation in $50 \mathrm{ml}$ tubes at 2000 to $3000 \times g$ for 5 min, preserved in DMSO buffer $(20 \%$ DMSO and $0.25 \mathrm{M}$ EDTA in NaCl-saturated water, Seutin et al. 1991) and nucleic acids subsequently extracted as described by Thornhill et al. (2006a). The data collection methods for the internal transcribed spacer region 2 (ITS2)-PCR, DGGE and microsatellite amplifications of Symbiodinium Clade B populations were provided in Thornhill et al. (2009).
The second fragment was placed directly into DMSO buffer and genomic DNA was extracted from the holobiont (i.e. host and Symbiodinium) using the DNeasy Tissue Kit (QIAGEN) according to the manufacturer's instructions. To examine the genetic diversity of Montastraea spp., a number of loci targeting the nuclear genome, including 4 microsatellites (Severance et al. $2004 \mathrm{a}, \mathrm{b})$ and 3 sequence-characterized regions derived from amplified fragment length polymorphisms (AFLP) (Fukami et al. 2004), were tested. These microsatellite and AFLP markers, however, failed to consistently amplify across all samples on numerous attempts and under modified (e.g. lower primer annealing temperatures and/or varying $\mathrm{MgCl}_{2}$ concentrations) PCR conditions. For this reason, as well as to avoid potential misinterpretations of characteristics such as null alleles and heterozygote deficiencies, the limited data derived from these markers are not presented here. As an alternative, an 891 bp intergenic region of noncoding mtDNA was targeted (Fukami et al. 2004). This noncoding mtDNA region is flanked by the cytochrome oxidase subunit I (COI) and tRNA ${ }^{\mathrm{MET}}$ genes and appears to have originated via a duplication of COI (Fukami \& Knowlton 2005). In contrast to the nuclear markers, the intergenic region of the mtDNA was readily amplified from all samples (a 900 bp amplicon) using the host-specific primers 'MCN1f' (5'-GAGCTGGGCTTCTTTAGAGTG-3') and 'MCN1r' (5'-GTGAGACTCGAACTCACTTTTC-3') (Fukami et al. 2004). Amplification was performed with the following thermocycling conditions: initial denaturation, $3 \mathrm{~min}$ at $94^{\circ} \mathrm{C} ; 35$ cycles of denaturation at $94^{\circ} \mathrm{C}$ for $45 \mathrm{~s}$, annealing at $55^{\circ} \mathrm{C}$ for $45 \mathrm{~s}$, and extension at $72^{\circ} \mathrm{C}$ for $90 \mathrm{~s}$; followed by a final extension of $10 \mathrm{~min}$ at $72^{\circ} \mathrm{C}$. To ensure that these primers were specific to the coral host, control PCRs were performed on DNA extracted 
from 5 Symbiodinium cultures representing ITS2 'types' from Clades A through F. These included cultures 292 ('type' A3), 141 ('type' B2), 152 ('type' C1), A001 ('type' D1a) and 133 ('type' F2) (ITS 'type' nomenclature sensu LaJeunesse 2001, 2002). In all cases, the MCN1f/MCN1r primers failed to generate a product from these cultures, indicating amplicons resulting from holobiont genomic DNA were of Montastraea spp., and not Symbiodinium, origin.

Amplification success was verified by $1 \times$ sodium borate agarose gel electrophoresis and amplicons subsequently purified using a QIAquick PCR Purification Kit (QIAGEN) according to the manufacturer's instructions. Products were bidirectionally sequenced using the MCN1f/MCN1r primer set by Geneway Research (Hayward). The resulting chromatograms were checked in Chromas v. 2.33 (Technelysium Pty) and sequences deposited in GenBank (www.ncbi.nlm.nih. gov) under accession numbers HM162916 to HM162925.

Molecular analyses. Symbiodinium ITS2 and multilocus microsatellite genotype data reported by Thornhill et al. (2009) were reanalyzed to evaluate the hypothesis that specificity in the Symbiodinium Clade B associations of Montastraea annularis and M. faveolata are correlated to the degree of genetic differentiation between these 2 coral species. Pairwise tests for Symbiodinium population differentiation, as accessed by $\Phi_{\mathrm{PT}}$ values (a haploid equivalent to $F_{\mathrm{ST}}$ ), were conducted by randomizing genotypes between pairs of populations (host-reef combinations) for both regions using GenAlEx v. 6.2 (Peakall \& Smouse 2006). Significance of the pairwise tests was assessed by 9999 permutations and with $\alpha=0.01$. Additionally, the number of genetically differentiated populations $(k)$ as well as the affiliation of samples ( $\mathrm{n}=3$ to 4 per host colony; see Thornhill et al. 2009) with similar multilocus genotypes to those populations were determined by Bayesian clustering analyses implemented in Structure v. 2.2 (Pritchard et al. 2000) using the default admixture model with correlated allele frequencies. Twenty replicate runs for $k$ values between 1 (no population differentiation) and 18 (the maximum number of distinct Symbiodinium Clade B multilocus genotypes sampled in any region) were performed, with each replicate run for $1 \times 10^{6}$ iterations following an initial burn-in of $1 \times 10^{5}$ iterations.

To examine the spatial and 'species' distributions of mtDNA genetic variation in Montastraea spp., the noncoding intergenic sequences were first aligned manually with MacClade v. 4.06 (Sinauer \& Associates). The numbers of polymorphic and parsimony informative sites as well as haplotype and nucleotide diversities were quantified using DnaSP v. 4.06 (Rozas et al. 2003). Percentages of adenine and thymine (A-T) and guanine and cytosine (G-C) content were calculated using BioEdit v. 7.0.9 (Hall 1999). To test for genetic differentiation between $M$. faveolata and $M$. annularis harboring Symbiodinium Clade B populations within each region, the nearest-neighbor statistic, Snn, (Hudson 2000) was estimated and significance assessed by 1000 permutations with $\alpha=0.01$ in DnaSP v. 4.06. Networks were also constructed separately for the Montastraea species haplotypes from Florida and the Bahamas with TCS v. 1.21 (Clement et al. 2000) using the default settings to visualize their relationships. Lastly, the networks were overlaid onto the Structure analyses (see above) to correlate the particular Symbiodinium Clade B multilocus genotypes/population hosted by a given colony relative to its specific Montastraea spp. mtDNA haplotype.

\section{RESULTS}

\section{Genetic diversity and symbiotic specificity of Symbiodinium}

Thornhill et al. (2009) presented the spatial and temporal distribution of Symbiodinium genotypes from the Montastraea spp. corals examined in the present study. Herein we summarized and reanalyzed these data in the context of host-symbiont specificity. At the resolu-

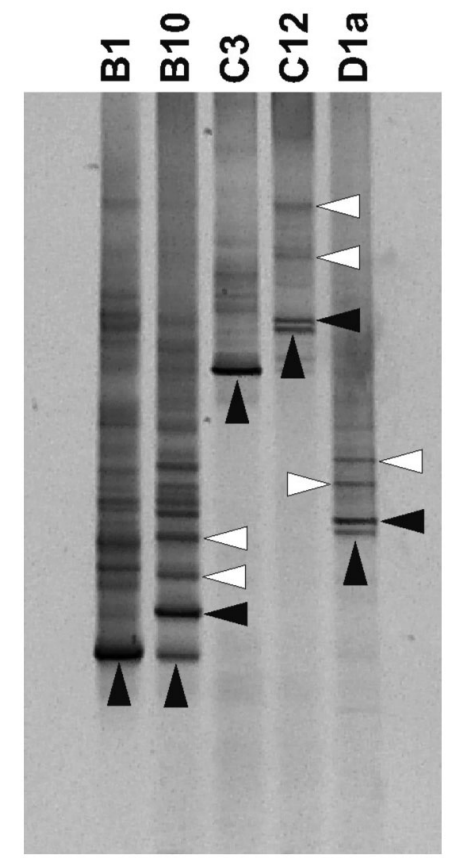

Fig. 2. Symbiodinium. Example PCR-DGGE profiles of the ITS2 region for Symbiodinium 'types' B1, B10, C3, C12 and D1a. Primary diagnostic bands are indicated for each Symbiodinium 'type' $(\boldsymbol{\Lambda})$. Fainter bands in each profile represent heteroduplexes $\left(\Delta_{i}\right.$ see LaJeunesse 2002$)$, rare ITS2 intragenomic variants (see Thornhill et al. 2007) or other methodological artifacts (see Thornhill et al. 2010). Profiles are presented as inverse images 
tion provided by ITS2 PCR-DGGE (see Thornhill et al. 2006a, LaJeunesse et al. 2009), a total of 5 different Symbiodinium ITS2 'types' were detected among the 60 colonies of $M$. faveolata and $M$. annularis we sampled. These included ITS2 'types' B1, B10, C3, C12 and D1a (Fig. 2). Two of these 'types' (i.e. B1 in both regions and $\mathrm{C} 12$ in the Exuma Cays) were recovered from both host species, whereas the other 'types' were found only in either $M$. faveolata (i.e. D1a at NP) or $M$. annularis (i.e. B10 at LG; C3 at ADM and AG). However, previous work on these tagged colonies detected additional host-Symbiodinium combinations, including B10 in M. faveolata (at LG) and D1a in M. annularis (at ADM and LG) (Thornhill et al. 2006a). Thus, at the ITS2 level, these 5 Symbiodinium 'types' appear to form relatively nonspecific symbioses with members of the $M$. annularis species complex.

The majority (50 of 60 colonies, $83.3 \%$ ) of Montastraea spp. examined associated with ITS2 'types' within Symbiodinium Clade B (i.e. B1 or B10). For these, 3 microsatellite loci specific to Symbiodinium Clade B were amplified to further investigate host-symbiont pairings at finer genetic scales. Twenty-four unique multilocus genotypes were detected among the Montastraea species colonies. Importantly, while colonies were either immediately adjacent, or in close proximity, to each other on the same reefs in Florida, no multilocus genotypes were shared among $M$. faveolata and $M$. annularis (Thornhill et al. 2009). The genetic isolation and fixed genotypic differences of Symbiodinium Clade B populations from $M$. faveolata and $M$. annularis in the Florida Keys were also evident in the Bayesian clustering analyses (Fig. 3a). In this case, although some reefs contained multiple inferred clusters, they were not shared between the host 'species' (Fig. 3a). Furthermore, all pairwise comparisons of Symbiodinium Clade B population differentiation from the different host 'species' were significant in the Florida Keys (Table 1). By contrast, 2 multilocus genotypes of Symbiodinium Clade B were shared between reefs as well as host 'species' for $M$. faveolata and $M$. annularis in the Exuma Cays (Fig. 3b). Given this, certain pairwise comparisons of population differentiation across the host 'species' were nonsignificant (Table 2). Taken together, Symbiodinium Clade B populations appear to be consistently host-specific in Florida, whereas such a pattern is less apparent for both $M$. faveolata and $M$. annularis in the Bahamas (Fig. 3).

\section{Genetic diversity and symbiotic specificity of Montastraea faveolata and $M$. annularis}

A total of $919 \mathrm{bp}$ of mitochondrial noncoding sequence data were successfully obtained for all (100\%) of the Montastraea faveolata and $M$. annularis colonies examined in this study $(\mathrm{n}=60)$. Of these, $100 \%$ of the nucleotide positions could be unambiguously aligned. This aligned data set is publicly available from www. auburn.edu/ santosr/sequencedatasets.htm.

Mitochondrial DNA is notoriously invariable among scleractinian corals (Medina et al. 1999, Shearer et al. 2002, Hellberg 2006). Despite this, nucleotide sequence diversity was detected among the sampled Montastraea faveolata and M. annularis. Specifically, a total of 11 positions $(1.2 \%)$ were found to be variable; of these, $4(0.4 \%)$ were parsimony-informative. Total nucleotide diversity $(\pi)$ was $0.00131 \pm 0.00013( \pm \mathrm{SD})$ and sequences were adenine and thymine (A-T) rich $(63.8 \%)$ compared with mean guanine and cytosine (G-C) content (36.2\%). Also, $M$. franski colonies were sampled wherever they were available to ensure the reported mtDNA variation did not result from inadvertent missampling of this Montastraea species. In all cases, $M$. franski could be readily distinguished from other Montastraea species by specific host mtDNA haplotypes, Symbiodinium associations (i.e. 'types' C3 or C12 with $M$. franski and 'type' B1 in other Montastraea species) and/or morphology (results not shown).

Ten different noncoding mtDNA haplotypes were detected among the 60 Montastraea faveolata and M. annularis (Table 3), for a haplotype diversity $(h)$ of $0.783 \pm 0.031( \pm \mathrm{SD})$. In the context of each host 'species', a total of 8 haplotypes were recovered from $M$. faveolata (designated A, B, E, F, G, H, I and J), of which 2 (i.e. F and G) and 4 (i.e. A, E, I and J) occurred exclusively in the Florida Keys and Exuma Cays, respectively (Table 3, Fig. 3). The remaining 2 haplotypes (i.e. $\mathrm{B}$ and $\mathrm{H}$ ) were found in $M$. faveolata of both regions (Fig. 3). Similar patterns were identified among M. annularis; 4 total haplotypes were detected (i.e. A, C, D and E), one (i.e. C) of which was exclusive to the Florida Keys, none occurred exclusively in the Exuma Cays and 3 (i.e. A, D and E) were shared between regions. Perhaps most notably, no haplotypes were shared between host 'species' in the Upper Florida Keys (Table 3). This genetic differentiation between Florida M. faveolata and $M$. annularis was reflected statistically by a significant nearest-neighbor comparison between the 2 species $(S n n=0.93750, p<0.0001)$. In contrast, the sharing of 2 haplotypes (i.e. A and E) among the different host morphospecies in the Exuma Cays (Table 3) led to a nonsignificant nearest-neighbor comparison for $M$. faveolata and $M$. annularis $(\mathrm{Snn}=$ 0.70667, p > 0.01).

To further explore the relationships among Montastraea faveolata and $M$. annularis noncoding mtDNA haplotypes, statistical parsimony (TCS) analyses were conducted for the Florida Keys and Exuma Cays populations. As noted above, no haplotypes were shared 
between host species in the Florida Keys. Instead, haplotype B was recovered from the majority $(\mathrm{n}=15)$ of M. faveolata while haplotype A accounted for the majority $(\mathrm{n}=14)$ of $M$. annularis (Fig. 3a). Three additional haplotyes were also found in $M$. faveolata (i.e. F, $\mathrm{G}$ and $\mathrm{H}$ ) and $M$. annularis (i.e. $\mathrm{C}, \mathrm{D}$ and $\mathrm{E}$ ) in the Florida Keys, albeit at low ( $\mathrm{n}=1$ or 2 ) frequencies. When the Symbiodinium Clade B multilocus geno- types associated with specific colonies are overlaid onto the network, correlations between symbiont diversity and distributions and host 'species' noncoding mtDNA haplotypes are readily apparent (Fig. 3a). For example, 4 Symbiodinium clusters associated with LG Montastraea species. One of these clusters associated exclusively with $M$. annularis (halpotype A), whereas the remaining 3 clusters were specific to $M$. faveolata

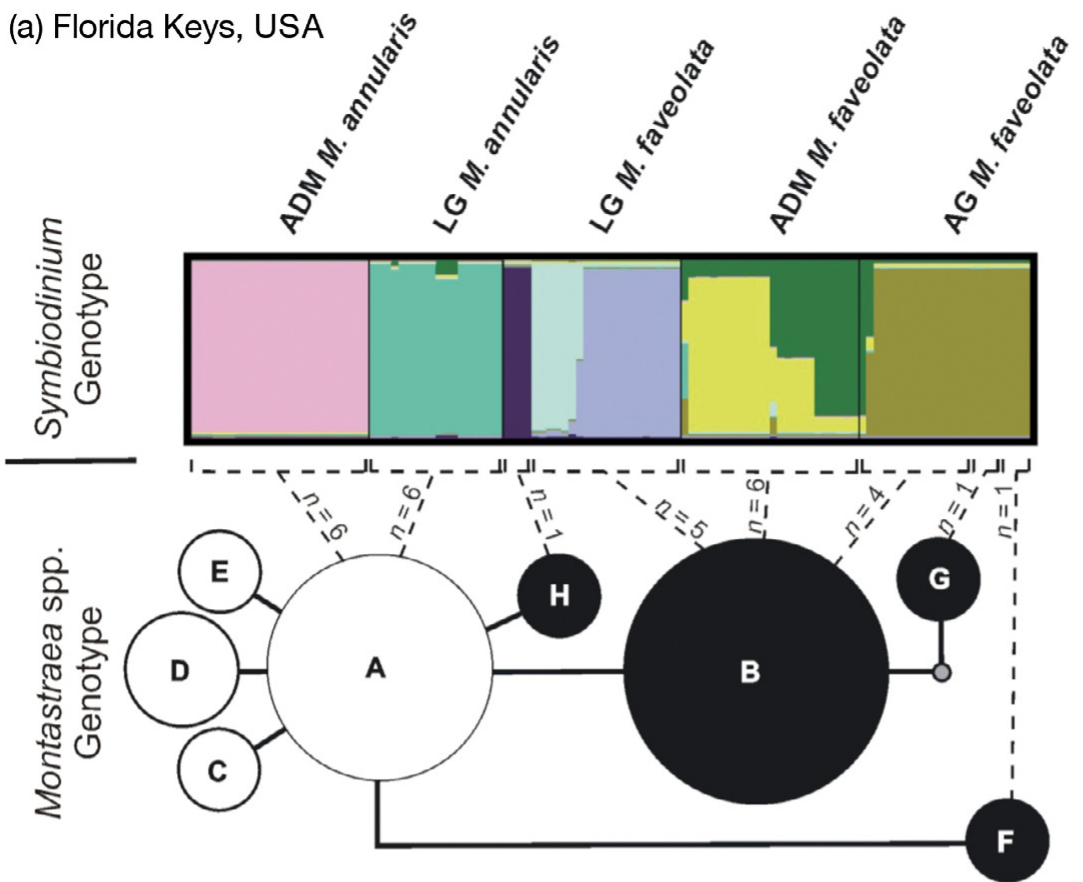

(b) Exuma Cays, Bahamas
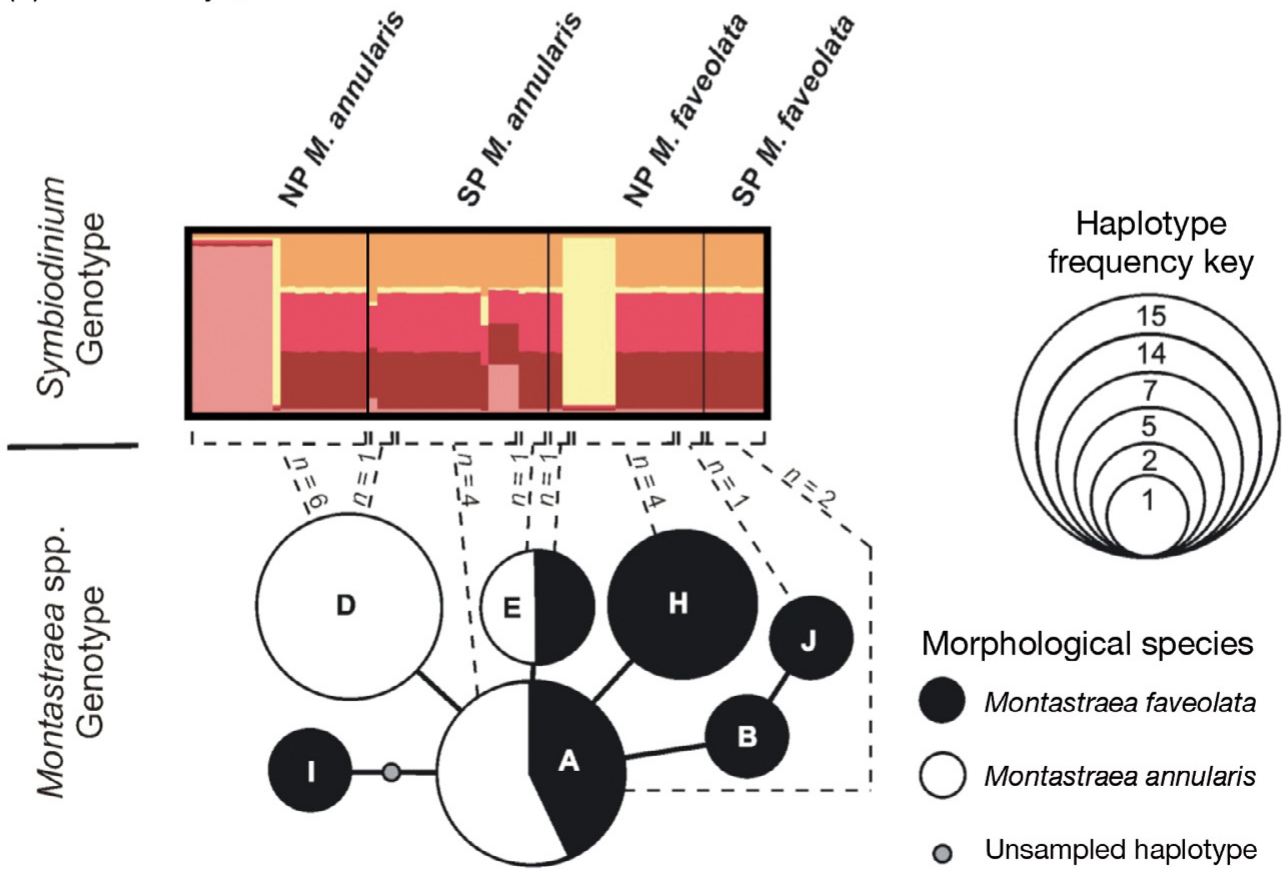
Table 1. Symbiodinium. Pairwise comparisons of $\Phi_{\mathrm{PT}}$ values (a haploid equivalent to $F_{\mathrm{ST}}$ ) among Symbiodinium Clade B populations originating from Montastraea faveolata and M. annularis in the Upper Florida Keys. See Fig. 1 for reef abbreviations. ${ }^{*} \mathrm{p}<0.0001$

\begin{tabular}{|lccccc|}
\hline $\begin{array}{l}\text { Reef and } \\
\text { host species }\end{array}$ & $\begin{array}{c}\text { LG } \\
\text { M. faveo- } \\
\text { lata }\end{array}$ & $\begin{array}{c}\text { ADM } \\
\text { M.faveo- } \\
\text { lata }\end{array}$ & $\begin{array}{c}\text { AG } \\
\text { M. faveo- } \\
\text { lata }\end{array}$ & $\begin{array}{c}\text { LG } \\
\text { M. annu- } \\
\text { laris }\end{array}$ & $\begin{array}{c}\text { ADM } \\
\text { lannu- } \\
\text { laris }\end{array}$ \\
\hline $\begin{array}{l}\text { LG } M \text {. faveolata } \\
\text { ADM M. faveolata }\end{array}$ & $0.669^{*}$ & $0.758^{*}$ & $0.774^{*}$ & $0.707^{*}$ \\
AG $M$. faveolata & & $0.682^{*}$ & $0.798^{*}$ & $0.876^{*}$ \\
LG $M$. annularis & & & $0.905^{*}$ & $0.942^{*}$ \\
ADM $M$. annularis & & & & $0.912^{*}$ \\
\hline
\end{tabular}

Table 2. Symbiodinium. Pairwise comparisons of $\Phi_{\mathrm{PT}}$ values (a haploid equivalent to $F_{\mathrm{ST}}$ ) among Symbiodinium Clade B populations originating from Montastraea faveolata and $M$. annularis in the Exuma Cays. See Fig. 1 for reef abbreviations. ${ }^{*} \mathrm{p}<0.01,{ }^{* *} \mathrm{p}<0.0001$; ns: not significant, $\mathrm{p}>0.01$

\begin{tabular}{|c|c|c|c|c|}
\hline $\begin{array}{l}\text { Reef and } \\
\text { host species }\end{array}$ & $\begin{array}{l}\text { NP } \\
\text { M. faveo- } \\
\quad \text { lata }\end{array}$ & $\begin{array}{l}\text { SP } \\
\text { M. faveo- } \\
\text { lata }\end{array}$ & $\begin{array}{l}\text { NP } \\
\text { M. annu- } \\
\text { laris }\end{array}$ & $\begin{array}{c}\text { SP } \\
\text { M. annu- } \\
\text { laris }\end{array}$ \\
\hline \multicolumn{2}{|c|}{ NP M. faveolata } & 0.190 (ns) & $0.335^{* *}$ & $0.203^{*}$ \\
\hline \multicolumn{2}{|c|}{ SP M. faveolata } & & 0.273 (ns) & $0.029(\mathrm{~ns})$ \\
\hline \multicolumn{2}{|c|}{ NP $M$. annularis } & & & $0.201^{* *}$ \\
\hline \multicolumn{2}{|c|}{ SP $M$. annularis } & & & \\
\hline
\end{tabular}

(i.e. 2 clusters with halplotype B and a third cluster with haplotype H) (Fig. 3a).

Compared with the genetic differentiation of Montastraea species in the Florida Keys, the network analysis clearly showed the 2 haplotypes (i.e. A and E) were shared between the morphospecies Montastraea faveolata and $M$. annularis in the Exuma Cays (Fig. 3b). Specifically, 3 colonies of $M$. faveolata and 4 colonies of $M$. annularis shared haplotype A (the most common $M$. annularis haplotype in the Upper Florida Keys), while one colony of $M$. faveolata and one colony of $M$. annularis shared haplotype E. The remaining Exuma Cay haplotypes were recovered in only 1 of the 2 host species. For $M$. faveolata, these included haplotypes B ( $\mathrm{n}=1$; note the difference in abundance relative to Upper Florida Keys specimens), $\mathrm{J}(\mathrm{n}=1), \mathrm{H}(\mathrm{n}=5)$ and $\mathrm{I}(\mathrm{n}=1)$, whereas the remaining $M$. annularis belonged to a single haplotype, D $(\mathrm{n}=7$ ). In this case, similar or identical Symbiodinium Clade B multilocus genotypes/populations were common among $M$. faveolata and $M$. annularis, including those with the shared host mtDNA haplotypes of A and E (Fig. 3b).

\section{DISCUSSION}

\section{Hybridization among Montastraea 'species'}

The results presented demonstrate that Montastraea faveolata and $M$. annularis in the Upper Florida Keys are genetically structured at the level of both host mtDNA haplotypes and their resident Symbiodinium Clade B populations. In contrast, an absence of genetic structure between $M$. faveolata and $M$. annularis in the Exuma Cays was due to mtDNA haplotypes being shared between them, and it is notable that Symbiodinium Clade B multilocus genotypes were also common between the host 'species' at these sites. Thus, this pattern is consistent with the hypothesis proposed by Thornhill et al. (2009) in that the fine-scale genotypic specificity of Symbiodinium Clade B associating with Montastraea is linked to the degree of genetic differentiation among the host 'species'. Although one potential explanation of the host mtDNA data is simply incomplete lineage sorting among Montastraea spe-

Fig. 3. Symbiodinium Clade B multilocus microsatellite and Montastraea spp. mtDNA genotypes as depicted by Structure and TCS analyses, respectively, for the (a) Upper Florida Keys and (b) Exuma Cays. For the Structure analyses (upper sections of panels a and b), results are presented as a graphical summary derived from 3 microsatellite loci specific to Symbiodinium Clade B. For (a) the Upper Florida Keys $k=8$, whereas for (b) the Exuma Cays $k=5$. Each sample ( $\mathrm{n}=3$ or 4 per host colony) is represented by a vertical line broken into segments to represent the estimated proportions of that sample's genome originating from each of the inferred clusters, and each cluster is represented by a different color. Sampling localities are separated by vertical black lines; reef and host species are noted above the graph (see Fig. 1 for reef abbreviations). For the TCS analyses (lower sections of panels a and b), Montastraea spp. haplotype networks based on $921 \mathrm{bp}$ of mtDNA are depicted using the $95 \%$ connectivity level. Sampled haplotypes are indicated by circles; missing or unsampled haplotypes are indicated by grey dots. Each branch (solid lines) indicates a single mutational difference and circle size is proportional to observed haplotype frequency (see legend, lower right). Haplotypes are shaded according to the morphological species of host from which the sample was collected (see legend, lower right). The clusters of Symbiodinium genotypes associated with each coral mtDNA haplotype are indicated by dotted lines connecting the TCS and Structure analyses. The number of coral colonies per haplotype associated with each Symbiodinium cluster is indicated along each dotted line. Coral colonies not linked to the Structure analyses by a dotted line harbored only Clade C Symbiodinium (i.e. ITS2 'type' C3 in the Upper Florida Keys and ITS2 'type' C12 in the Exuma Cays) within the detection limits for ITS2 PCR-DGGE (see Thornhill et al. 2006a, LaJeunesse et al. 2009) 
Table 3. Montastraea annularis and M. faveolata. Distribution of mtDNA intergenic region haplotypes among host species, reefs and colonies. See Fig. 1 for reef abbreviations

\begin{tabular}{|llll|}
\hline $\begin{array}{l}\text { Montastraea spp. } \\
\text { htDNA } \\
\text { haplotype }\end{array}$ & $\begin{array}{l}\text { Coral morpho- } \\
\text { logical } \\
\text { species }\end{array}$ & $\begin{array}{l}\text { Reef and } \\
\text { colony nos. }\end{array}$ & $\begin{array}{l}\text { GenBank } \\
\text { accession } \\
\text { nos. }\end{array}$ \\
\hline A & M. annularis & $\begin{array}{l}\text { ADM 1-6, LG 1-6; } \\
\text { AG 1, 6; SP 2-4, 6 }\end{array}$ & HM162916 \\
A & M. faveolata & SP 1-3 & HM162916 \\
B & M. faveolata & ADM 1-6; LG 1-3, 5, 6; & HM162917 \\
C & M. annularis & AG 5 4-6; SP 5 & HM162918 \\
D & M. annularis & AG 2, 4; NP 1-6; SP 5 & HM162919 \\
E & M. annularis & AG 3; SP 1 & HM162920 \\
E & M. faveolata & NP 3 & HM162920 \\
F & M. faveolata & AG 3 & HM162921 \\
G & M. faveolata & AG 1 & HM162923 \\
H & M. faveolata & LG 4; NP 1, 2, 4, 6; SP 6 & HM162924 \\
I & M. faveolata & SP 4 & HM162925 \\
J & M. faveolata & NP 5 & \\
\hline
\end{tabular}

ers to hybridization have not been evaluated thus far in members of the $M$. annularis species complex, they may also play an important role in determining the success of coral zygotes and larvae of hybrid origin. For example, the IndoPacific species Acropora hyacinthus and $A$. cytherea are sympatric, spawn synchronously and are highly crossfertile (Márquez et al. 2002). Despite this seemingly large potential for hybridization, A. hyacinthus and A. cytherea remain statistically distinguishable genetic lineages, signifying infrequent introgressive hybridization in nature due to either pre- or postzygotic reproductive barriers (Márquez et al. 2002). In the case of Montastraea spp., the factors ultimately influencing hybridization or incomplete lineage sorting in some regions and divergence in

cies in the Exuma Cays, this possibility seems unlikely considering the distinctly different pattern observed in the Upper Florida Keys and elsewhere (Budd \& Pandolfi 2004, Fukami et al. 2004). Rather, a likelier scenario is that regional differences in interspecies hybridization (either in the geologic past or contemporarily) underlie these observations. Geologic evidence, for instance, suggests that introgressive hybridization occurred in the Bahamas during the sea level and climatic fluctuations of the late Pleistocene (Budd \& Pandolfi 2004). If this is the case, some type of environmental, prezygotic and/or postzygotic barriers to interspecies reproduction must have been present historically (and/or is present today) in these coral lineages from the Upper Florida Keys (but not in the Exuma Cays), at least among the colonies and reefs investigated in the present study.

Previous reproductive studies have documented Montastraea faveolata and $M$. annularis as spawning synchronously and sympatrically in both the Florida Keys and the Exuma Cays, suggesting environmental barriers to hybridization are limited (Szmant et al. 1997, Levitan et al. 2004, see also Knowlton et al. 1997). Furthermore, experimental crossings of $M$. faveolata and M. annularis have sometimes, but not always, resulted in planula larvae, demonstrating an incompleteness of prezygotic barriers (e.g. Knowlton et al. 1997, Szmant et al. 1997, Levitan et al. 2004). However, such experiments in Montastraea spp. have been conducted in the absence of conspecific sperm or eggs and it is possible that interspecies fertilization declines precipitously when intra- and interspecies gametes compete for fertilization opportunities, as would be the typical case during a spawning event. Although postzygotic barri- others remain unknown. However, the data presented here, combined with previous work (Budd \& Pandolfi 2004, Fukami et al. 2004), suggest the 'species' boundaries between $M$. faveolata and $M$. annularis are weaker in the Exuma Cays than in other regions of the Caribbean Sea.

When considering the Montastraea genetic data, it is important to recognize the relatively slow rate at which mtDNA generally evolves in scleractinian corals (Shearer et al. 2002, Hellberg 2006), including the 'species' examined here (Medina et al. 1999). For instance, Fukami \& Knowlton (2005) found just 25 variable characters from the entire mitochondrial genomes $(\sim 16.2 \mathrm{kbp})$ of the 3 members of the $M$. annularis species complex (notably, 16 of these characters came from the specimen of $M$. franksi that was sequenced). Based on this level of genetic variability and their split from other Montastraea at 3 to 4 million years ago, they estimated Montastraea mtDNA diverges at a maximum rate of only 0.03 to $0.04 \%$ per 1 million years (Fukami \& Knowlton 2005). Furthermore, fossil evidence indicates that $M$. annularis and $M$. cavernosa diverged approximately 24 million years ago and yet these congeners differ by merely $2.4 \%$ in COI mtDNA (Medina et al. 1999). Given this remarkably low level of mtDNA divergence, any variation, even the difference of a single base pair, has the potential to be significant in an evolutionary context. As a result, it is entirely possible (and in fact likely) that much higher levels of genetic differentiation would be measured from the nuclear genomes of these Montastraea species. While it would have been ideal to evaluate this possibility with a suite of nuclear loci, candidates identified from the published literature and screened here 
proved problematic among our samples, thus making confident detection of genotypes unreliable, especially among potential heterozygotes. The specific reasons (e.g. primer design or primers-template mismatch) surrounding the issues with these markers require further investigation.

\section{Specificity in cnidarian-Symbiodinium associations}

The proximate processes driving specificity remain unknown in most cnidarian-Symbiodinium relationships, including Montastraea faveolata and M. annularis sampled here in the Upper Florida Keys. Despite this, recent research has provided considerable insight into some of the mechanisms underlying recognition and specificity of host-symbiont pairings in these systems. For those cnidarians acquiring their Symbiodinium from the environment anew at each generation (i.e. horizontal acquisition), locally available Symbiodinium diversity provides an initial limit on the number of potential host-symbiont combinations. Initial infection is often nonspecific followed by a winnowing process leading to specificity in hours to months (e.g. Coffroth et al. 2001, Little et al. 2004, Rodriguez-Lanetty et al. 2006a, Thornhill et al. 2006b). Once Symbiodinium cells enter the cnidarian gastrovascular cavity, the prephagocytic recognition process for a number of corals involves interactions between Symbiodinium cell surface glycans and host lectins (Wood-Charlson et al. 2006, Kvennefors et al. 2008). Following this initial recognition, Symbiodinium cells are phagocitized and housed within intracellular vacuoles of the host gastroderm (e.g. Wakefield \& Kempf 2001) where they apparently prevent lysosomal maturation that would otherwise lead to their digestion (Fitt \& Trench 1983, Chen et al. 2003). During this time, certain coral-dinoflagellate pairings fail to maintain a suitable and stable symbiosis owing to either an incompatibility between symbiotic partners or an inappropriate microhabitat (e.g. temperature and/or light regimes) for either the coral host or the dinoflagellate endosymbiont. In hostsymbiont combinations that fail to form sustained symbioses, postphagocytic winnowing involves host cell apoptosis, proteolysis and immune system responses (Dunn \& Weis 2009, Voolstra et al. 2009). In contrast, there are minimal to relatively minor postphagocytic changes in host gene expression of pairings that lead to a successful symbiosis, suggesting that Symbiodinium inhabit their hosts by either escaping detection or active inhibition of the host response (Barneah et al. 2006, Rodriguez-Lanetty et al. 2006b, Voolstra et al. 2009). Finally, competition within a host among competent Symbiodinium 'types' may also play a role in determining the dominant endosymbiont (Fitt 1985, Coffroth et al. 2001, Little et al. 2004, Thornhill et al. 2006b). Thus, although a variety of phenomena are ultimately responsible for hostsymbiont specificity, it appears that the overall process is relaxed when hybridization and introgression occur between coral species, as is apparently the case for Montastraea species in the Exuma Cays.

The Symbiodinium multilocus microsatellite genotypes detected here exhibited local and regional endemism, with no genotypes shared between the Upper Florida Keys and Exuma Cays (Thornhill et al. 2009). This finding was consistent with other studies (Santos et al. 2003, Howells et al. 2009) indicating that endemism may be a common characteristic of Symbiodinium populations. Unfortunately, the presence of endemic Symbiodinium populations hinders definitive determination of the relative influence of host versus symbiont genotype on symbiotic specificity in Montastraea spp. One alternative interpretation for our data, for instance, is that Symbiodinium genotypes from the Upper Florida Keys are more host specific than are their Exuma Cays counterparts, regardless of coral hybridization patterns. Although the correlation between host genetic distinctiveness and endosymbiont genotype argues against this possibility and for coral genotype and hybridization involvement in host-symbiont specificity, the complexity of these symbioses and endemic nature of Symbiodinium populations leaves possible such alternative interpretations.

Much clearly remains to be discovered regarding the specificity and/or flexibility of these dynamic and fascinating symbioses. Our results represent a modest first step towards documenting the fine-scale genotypic specificity and complexity of cnidarian-Symbiodinium relationships. These findings are noteworthy since commonly used molecular markers (e.g. ribosomal genes and their spacers) provide a much 'coarser' resolution of Symbiodinium genetic diversity, thereby suggesting flexible symbioses for both Montastraea faveolata and $M$. annularis (Toller et al. 2001, LaJeunesse 2002, Thornhill et al. 2006a). Instead, application of fine-scale symbiont microsatellites, in combination with host mtDNA markers, revealed strong specificity as well as potential mechanisms (i.e. hybridization and introgression) affecting the intimacy of these relationships. Further investigation of invertebrate-Symbiodinium specificity is of particular interest in predicting how such symbioses will respond to climate change. For example, stressors like high temperature and light levels can disrupt coral-algal symbioses, often leading to host mortality and ecosystem shifts (e.g. HoeghGuldberg 1999, Sampayo et al. 2008). Therefore, it is important to better determine whether, and under what circumstances, such events drive surviving coral and 
Symbiodinium populations into novel host-symbiont combinations (Goulet et al. 2008, Jones et al. 2008, LaJeunesse et al. 2009, Thornhill et al. 2009). Hybridization provides one potential mechanism that may relax symbiotic specificity and increase the numbers of viable host-Symbiodinium associations in the future.

Acknowledgements. This project was made possible by a Henry L. and Grace Doherty Charitable Foundation Coastal Studies Research Fellowship awarded to K.D. Additional funding was provided by the Howard Hughes Medical Institute (HHMI) Undergraduate Science Program. We gratefully acknowledge the assistance of W. K. Fitt, W. L. Hatleberg, L. A. Newcomb and G. W. Schmidt in conducting this work. R. K. Trench, 3 anonymous reviewers and students enrolled in the course Evolution (Bio 216, spring semester 2010) at Bowdoin College provided insightful comments that improved the manuscript. This is Auburn University Marine Biology Program contribution number 76 .

\section{LITERATURE CITED}

Barneah O, Benayahu Y, Weis VM (2006) Comparative proteomics of symbiotic and aposymbiotic juvenile soft corals. Mar Biotechnol 8:11-16

Barnes DJ, Chalker BE (1990) Calcification and photosynthesis in reef-building corals and algae. In: Dubinski Z (ed) Ecosystems of the world: 25 coral reefs. Elsevier Science, Amsterdam, p 109-131

Barshis DJ, Stillman JH, Gates RD, Toonen RJ, Smith LW, Birkelands C (2010) Protein expression and genetic structure of the coral Porites lobata in an environmentally extreme Samoan back reef: Does host genotype limit phenotypic plasticity? Mol Ecol 19:1705-1720

Benzie JAH (1999) Genetic structure of coral reef organisms: ghosts of dispersal past. Am Zool 39:131-145

Bongaerts P, Riginos C, Ridgway T, Sampayo EM and others (2010) Genetic divergence across habitats in the widespread coral Seriatopora hystrix and its associated Symbiodinium. PLoS ONE 5:e10871

Budd AF, Pandolfi JM (2004) Overlapping species boundaries and hybridization within the Montastraea 'annularis' reef coral complex in the Pleistocene of the Bahama Islands. Paleobiology 30:396-425

Chen MC, Cheng YM, Sung PJ, Kuo CE, Fang LS (2003) Molecular identification of Rab7 (ApRab7) in Aiptasia pulchella and its exclusion from phagosomes harboring zooxanthellae. Biochem Biophys Res Commun 308:586-595

Clement M, Posada D, Crandall KA (2000) TCS: a computer program to estimate gene genealogies. Mol Ecol 9: 1657-1659

> Coffroth MA, Santos SR (2005) Genetic diversity of symbiotic dinoflagellates in the genus Symbiodinium. Protist 156:19-34

> Coffroth MA, Santos SR, Goulet TL (2001) Early ontogenetic expression of specifity in cnidarian-algal symbiosis. Mar Ecol Prog Ser 222:85-96

> Correa AMS, Baker AC (2009) Understanding diversity in coral-algal symbiosis: a cluster-based approach to interpreting fine-scale genetic variation in the genus Symbiodinium. Coral Reefs 28:81-93

> Diekmann OE, Bak RPM, Starn WT, Olsen JL (2001) Molecular genetic evidence for probable reticulate speciation in the coral genus Madracis from a Caribbean fringing reef slope. Mar Biol 139:221-233
Dunn SR, Weis VM (2009) Apoptosis as a post-phagocytic winnowing mechanism in a coral-dinoflagellate mutualism. Environ Microbiol 11:268-276

Fitt WK (1985) Effect of different strains of the zooxanthellae Symbiodinium microadriaticum on growth and survival of their coelenterate and molluscan hosts. Proc 5th Int Coral Reef Congr, Tahiti 6:131-136

Fitt WK, Trench RK (1983) Endocytosis of the symbiotic dinoflagellate Symbiodinium microadriaticum Freudenthal by endodermal cells of the scyphistomae of Cassiopeia xamachana and resistance of the algae to host digestion. J Cell Sci 64:195-212

> Fukami H, Knowlton N (2005) Analysis of complete mitochondrial DNA sequences of three members of the Montastraea annularis coral species complex (Cnidaria, Anthozoa, Scleractinia). Coral Reefs 24:410-417

Fukami H, Budd AF, Levitan DR, Jara J, Kersanach R, Knowlton N (2004) Geographic differences in species boundaries among members of the Montastraea annularis complex based on molecular and morphological markers. Evolution 58:324-337

> Goreau TF (1959) The ecology of Jamaican coral reefs. I. Species composition and zonation. Ecology 40:67-90

Goulet TL (2006) Most corals may not change their symbionts. Mar Ecol Prog Ser 321:1-7

Goulet TL, LaJeunesse TC, Fabricius KE (2008) Symbiont specificity and bleaching susceptibility among soft corals in the 1998 Great Barrier Reef mass coral bleaching event. Mar Biol 154:795-804

Hall TA (1999) BioEdit: a user-friendly biological sequence alignment editor and analysis program for Windows 95/98/NT. Nucleic Acids Symp Ser 41:95-98

Hellberg ME (2006) No variation and low synonymous substitution rates in coral mtDNA despite high nuclear variation. BMC Evol Biol 6:24

> Hoegh-Guldberg O (1999) Climate change, coral bleaching, and the future of the world's coral reefs. Mar Freshw Res 50:839-866

> Howells EJ, van Oppen MJH, Willis BL (2009) High genetic differentiation and cross-shelf patterns of genetic diversity among Great Barrier Reef populations of Symbiodinium. Coral Reefs 28:215-225

> Hudson RR (2000) A new statistic for detecting genetic differentiation. Genetics 155:2011-2014

- Jones AM, Berkelmans R, van Oppen MJH, Mieog JC, Sinclair W (2008) A community change in the algal endosymbionts of a scleractinian coral following a natural bleaching event: field evidence of acclimatization. Proc Biol Sci 275:1359-1365

Knowlton N, Weil E, Weigt LA, Guzmán HM (1992) Sibling species in Montastraea annularis, coral bleaching, and the coral climate record. Science 255:330-333

> Knowlton N, Maté JL, Guzmán HM, Rowan R, Jara J (1997) Direct evidence for reproductive isolation among the three species of the Montastraea annularis complex in Central America (Panamá and Honduras). Mar Biol 127:705-711

> Kvennefors ECE, Leggat W, Hoegh-Guldberg O, Degnan BM, Barnes AC (2008) An ancient and variable mannose-binding lectin from the coral Acropora millepora binds both pathogens and symbionts. Dev Comp Immunol 32: 1582-1592

> LaJeunesse TC (2001) Investigating the biodiversity, ecology, and phylogeny of endosymbiotic dinoflagellates in the genus Symbiodinium using the ITS region: in search of a 'species' level marker. J Phycol 37:866-880

LaJeunesse TC (2002) Diversity and community structure of symbiotic dinoflagellates from Caribbean coral reefs. Mar Biol 141:387-400 
LaJeunesse TC, Smith RT, Finney J, Oxenford H (2009) Outbreak and persistence of opportunistic symbiotic dinoflagellates during the 2005 Caribbean mass coral 'bleaching' event. Proc Biol Sci 276:4139-4148

- Levitan DR, Fukami H, Jara J, Kline D and others (2004) Mechanisms of reproductive isolation among sympatric broadcast-spawning corals of the Montastraea annularis species complex. Evolution 58:308-323

Little AF, van Oppen MJH, Willis BL (2004) Flexibility in algal endosymbioses shapes growth in reef corals. Science 304: 1492-1494

Márquez LM, van Oppen MJH, Willis BL, Miller DJ (2002) Sympatric populations of the highly cross-fertile coral species Acropora hyacinthus and A. cytherea are genetically distinct. Proc Biol Sci 269:1289-1294

> Medina M, Weil E, Szmant AM (1999) Examination of the Montastraea annularis species complex (Cnidaria, Scleractinia) using ITS and COI sequences. Mar Biotechnol $1: 89-97$

Miller KJ, Benzie JA (1997) No clear genetic distinction between morphological species within the genus Platygyra. Bull Mar Sci 61:907-917

> Peakall R, Smouse PE (2006) GenAlEx 6: genetic analysis in Excel. Population genetic software for teaching and research. Mol Ecol Notes 6:288-295

Pochon X, Garcia-Cuetos L, Baker AC, Castella E, Pawlowski J (2007) One-year survey of a single Micronesian reef reveals extraordinarily rich diversity of Symbiodinium types in soritid foraminifera. Coral Reefs 26:867-882

> Pritchard JK, Stephens M, Donnelly P (2000) Inference of population structure using multilocus genotype data. Genetics 155:945-959

Richmond RH, Hunter CL (1990) Reproduction and recruitment of corals: comparisons among the Caribbean, the Tropical Pacific, and the Red Sea. Mar Ecol Prog Ser 60:185-203

Rodriguez-Lanetty M, Wood-Charlson EM, Hollingsworth LL, Krupp DA, Weis VM (2006a) Temporal and spatial infection dynamics indicate recognition in the early hours of a dinoflagellate/coral symbiosis. Mar Biol 149:713-719

Rodriguez-Lanetty M, Phillips WS, Weis VM (2006b) Transcriptome analysis of a cnidarian-dinoflagellate mutualism reveals complex modulation of host gene expression. BMC Genomics 7:23

Rozas J, Sánchez-DelBarrio JC, Messeguer X, Rozas R (2003) DnaSP, DNA polymorphism analyses by the coalescent and other methods. Bioinformatics 19:2496-2497

Sampayo EM, Ridgway T, Bongaerts P, Hoegh-Gulberg O (2008) Bleaching susceptibility and mortality of corals are determined by fine-scale differences in symbiont type. Proc Natl Acad Sci USA 105:10444-10449

Sampayo EM, Dove S, LaJeunesse TC (2009) Cohesive molecular genetic data delineate species diversity in the dinoflagellate genus Symbiodinium. Mol Ecol 18: 500-519

Santos SR, Gutiérrez-Rodríguez C, Lasker HR, Coffroth MA (2003) Symbiodinium sp. associations in the gorgonian Pseudopterogorgia elisabethae in the Bahamas: high levels of genetic variability and population structure in symbiotic dinoflagellates. Mar Biol 143:111-120

Seutin G, White BN, Boag PT (1991) Preservation of avian blood and tissue samples for DNA analysis. Can J Zool 69: 82-92

> Severance EG, Szmant AM, Karl SA (2004a) Microsatellite loci isolated from the Caribbean coral Montastraea annularis. Mol Ecol Notes 4:74-76

Severance EG, Szmant AM, Karl SA (2004b) Single-copy gene markers isolated from the Caribbean coral, Montastraea annularis. Mol Ecol Notes 4:167-169
Shearer TL, van Oppen MJH, Romano SLR, Wörheide G (2002) Slow mitochondrial DNA sequence evolution in the Anthozoa (Cnidaria). Mol Ecol 11:2475-2487

> Stat M, Carter D, Hoegh-Guldberg O (2006) The evolutionary history of Symbiodinium and scleractinian hosts - symbiosis, diversity, and the effect of climate change. Perspect Plant Ecol Evol Syst 8:23-43

Szmant AM (1986) Reproductive ecology of Caribbean reef corals. Coral Reefs 5:43-54

Szmant AM, Weil E, Miller MW, Colon DE (1997) Hybridization within the species complex of Montastraea annularis. Mar Biol 129:561-572

Thornhill DJ, LaJeunesse TC, Kemp DW, Fitt WK, Schmidt GW (2006a) Multi-year, seasonal genotypic surveys of coral-algal symbioses reveal prevalent stability or postbleaching reversion. Mar Biol 148:711-722

Thornhill DJ, Daniel MW, LaJeunesse TC, Fitt WK, Schmidt GW (2006b) Natural infections of aposymbiotic Cassiopea xamachana from environmental pools of Symbiodinium. J Exp Mar Biol Ecol 338:50-56

> Thornhill DJ, LaJeunesse TC, Santos SR (2007) Measuring rDNA diversity in eukaryotic microbial systems: how intragenomic variation, pseudogenes, and PCR artifacts confound biodiversity estimates. Mol Ecol 16: 5326-5340

Thornhill DJ, Kemp DW, Bruns BU, Fitt WK, Schmidt GW (2008) Correspondence between cold tolerance and temperate biogeography in a western Atlantic Symbiodinium (Dinophyta) lineage. J Phycol 44:1126-1135

Thornhill DJ, Xiang Y, Fitt WK, Santos SR (2009) Reef endemism, host specificity and temporal stability in populations of symbiotic dinoflagellates from two ecologically dominant Caribbean corals. PLoS ONE 4:e6262

Thornhill DJ, Kemp DW, Sampayo EM, Schmidt GW (2010) Comparative analyses of amplicon migration behavior in differing denaturing gradient gel electrophoresis (DGGE) systems. Coral Reefs 29:83-91

Toller WW, Rowan R, Knowlton N (2001) Zooxanthellae of the Montastraea annularis species complex: patterns of distribution of four taxa of Symbiodinium on different reefs and across depths. Biol Bull (Woods Hole) 201:348-359

Trench RK (1993) Microalgal-invertebrate symbioses: a review. Endocytobiosis Cell Res 9:135-175

Van Oppen MJH, Willis BL, van Vugt H, Miller DJM (2000) Examination of species boundaries in the Acropora cervicornis group (Scleractinia, Cnidaria) using nuclear DNA sequence analysis. Mol Ecol 9:1363-1373

Veron JEN (1995) Corals in space and time. The biogeography and evolution of the Scleractinia. UNSW Press, Sydney

> Vollmer SV, Palumbi SR (2002) Hybridization and the evolution of reef coral diversity. Science 296:2023-2025

> Voolstra CR, Schwarz JA, Schnetzer J, Sunagawa S and others (2009) The host transcriptome remains unaltered during the establishment of coral-algal symbioses. Mol Ecol 18:1823-1833

- Wakefield T, Kempf S (2001) Development of host- and symbiont-specific monoclonal antibodies and confirmation of the origin of the symbiosome membrane in a cnidarian-dinoflagellate symbiosis. Biol Bull (Woods Hole) 200: 127-143

> Willis BL, van Oppen MJH, Miller DJ, Vollmer SV, Ayre DJ (2006) The role of hybridization in the evolution of reef corals. Annu Rev Ecol Evol Syst 37:489-517

> Wood-Charlson EM, Hollingsworth LH, Krupp DA, Weis VM (2006) Lectin/glycan interactions play a role in recognition in a coral/dinoflagellate symbiosis. Cell Microbiol 8: 1985-1994

Submitted: April 27, 2010; Accepted: October 12, 2010

Proofs received from author(s): December 3, 2010 